\title{
A QUÍMICA ATMOSFÉRICA NO BRASIL DE 1790 A 1853
}

\author{
Adílio Jorge Marques e Carlos A. L. Filgueiras*\# \\ Instituto de Química, Universidade Federal do Rio de Janeiro, CT, Bl. A, CP 68563, 21945-970 Rio de Janeiro - RJ, Brasil
}

Recebido em 8/10/09; aceito em 17/3/10; publicado na web em 29/6/10

\begin{abstract}
ATMOSPHERIC CHEMISTRY IN BRAZIL FROM 1790 TO 1853. Scarcely any mention is made today of investigations carried out in Brazil during the period above on the science of the atmosphere. Yet the study of these cases reveals much about the milieu of a few devoted men who laboured to pursue a scientific career. That such an arcane topic has been the concern of investigators at such an early date may come as a surprise to many. The subject was an oddity as a field of study anywhere at the time, and its history deserves the attention of present-day chemists.
\end{abstract}

Keywords: atmospheric chemistry; early chemistry in Brazil.

Pouco se conhece a respeito de algumas investigações pioneiras da Química atmosférica levadas a cabo no Brasil desde o final do século XVIII. Como se trata de assunto tão presente nas cogitações dos cientistas dos tempos atuais, é importante saber que houve aqui estudiosos preocupados em pesquisar o tema em épocas mais distantes da História do Brasil. É surpreendente descobrir a existência de trabalhos, tanto experimentais como especulativos, sobre fenômenos atmosféricos numa sociedade ainda bastante acientífica. Todavia, mesmo com as deficiências que se possam apontar naqueles trabalhos, com a vantagem de se estar no futuro, é preciso reconhecer essas contribuições como das primeiras no hemisfério ocidental e mesmo no mundo sobre o tema. O presente artigo trata, sobretudo, de duas abordagens completamente distintas no estudo da ciência atmosférica, uma ainda na era colonial, e a outra já em meados do período imperial.

A Química do século XVIII foi dominada pelos estudos dos gases, suas propriedades e reações. Esta foi a chamada Química Pneumática, que culminou no trabalho de Lavoisier, dando uma explicação satisfatória para o antigo problema que desafiava a humanidade desde seus primórdios, que era entender o processo da combustão dos corpos. Foi o desenvolvimento da Química Pneumática que permitiu a Lavoisier estabelecer os princípios da Química Moderna, que nos acompanham até hoje. Entre estes princípios estão o entendimento de que o processo da combustão é uma reação dos corpos combustíveis com o oxigênio, que o ar não é uma substância elementar, mas sim uma mistura de gases, e que a água tampouco é elementar, mas um composto, o qual pode ser quebrado em seus constituintes, os gases hidrogênio e oxigênio, assim como estes podem ser recombinados para fazer a síntese da água. Para Lavoisier esses processos podiam e deviam ser investigados não só de forma qualitativa, mas também quantitativamente, estabelecendo relações precisas entre as quantidades dos reagentes e dos produtos nas reações químicas.

Um marco decisivo na Química Pneumática foi a descoberta, em 1756, por Joseph Black (1728-1799), professor de Química e Medicina na Universidade de Edimburgo, do ar fixo, que conhecemos como dióxido de carbono. Black descobriu, ao investigar a magnesia alba, ou carbonato de magnésio, que ela efervescia ao ser posta em ácidos, e o ar liberado coincidia com aquele produzido nas fermentações levadas a cabo nas cervejarias. Ele mostrou de forma inequívoca que se tratava de um gás diferente do ar atmosférico e

*e-mail: calf@iq.ufrj.br

\#Programa de Pós-Graduação em História das Ciências e das Técnicas e Epistemologia pela primeira vez ficou demonstrada a existência de um gás distinto do ar. O nome ar fixo foi cunhado por Black em virtude de aquele ar estar fixado num sólido, a magnesia alba, e poder ser liberado por uma ação química. ${ }^{1}$ Com o decorrer do século XVIII vários outros gases foram descobertos: o ar inflamável, ou hidrogênio, por Henry Cavendish (1731-1810), em 1766; o ar mefítico, ou nitrogênio, de Daniel Rutherford (1749-1819), em 1772; e o ar do fogo, de Carl Wilhelm Scheele (1742-1786), em 1772, chamado em 1774 de ar desflogisticado por Joseph Priestley (1733-1804), e de ar vital, mais tarde oxigênio, por Antoine-Laurent Lavoisier (1743-1794), em $1776 .{ }^{1}$ Em suma, havia uma grande atividade em vários países europeus envolvendo o estudo dos gases.

A partir de 1783 instalou-se na Europa a voga dos aeróstatos, ou balões, iniciada na França pelos irmãos Joseph (1740-1810) e Etienne Montgolfier (1745-1799), que construíram balões de ar quente que voaram a grandes distâncias com bastante êxito. ${ }^{1}$ Aos balões de ar quente se seguiram no mesmo ano os balões de hidrogênio, de autoria de Jacques Alexandre César Charles (1746-1823) e Nicolas Louis Robert (1761-1828). ${ }^{1}$ A invenção dos balões de ar quente pelos Montgolfier era, de certa forma, uma reinvenção independente, uma vez que em 1709 o brasileiro Bartolomeu Lourenço de Gusmão (16851724) já havia feito vários ensaios com pequenos balões deste tipo em Lisboa, na presença do Rei D. João V e sua corte, que incluía o Núncio Apostólico Michelangelo dei Conti, que descreveu o episódio minuciosamente em carta ainda existente nos Arquivos do Vaticano. Este mesmo Cardeal Conti viria a reinar como Papa, com o nome de Inocêncio XIII (1721-1724)..$^{2-4}$

Logo após os vôos dos balões dos irmãos Montgolfier, em 1784, quatro alunos de Química do Prof. Domingos Vandelli, na Universidade de Coimbra, lançaram-se à tarefa de também construir balões, tanto de ar quente como de hidrogênio. Entre estes alunos, José Álvares Maciel e Vicente Coelho de Seabra Silva Telles eram brasileiros. ${ }^{5}$ De acordo com a Gazeta de Lisboa, a máquina aerostática era um balão de ar quente de forma piramidal cônica, de 30 palmos de diâmetro e 45 de altura ${ }^{6}$ Ela subiu aos ares em duas ocasiões, em 25 e 27 de junho de 1784. Esta última data coincide com o nascimento do filho de Domingos Vandelli, Alexandre, do qual este relato se ocupará mais adiante.

Assim relata a Gazeta uma das ascensões: esta máquina se achava prestes no laboratório químico da Universidade para ser lançada aos ares a 15 de Junho; mas, querendo os autores dela, que são Tomás José de Miranda e Almeida, alferes do regimento de cavalaria de Elvas, José Álvares Maciel, Salvador Caetano de Carvalho e Vicente 
Coelho de Seabra, todos aplicados às ciências naturais, autorizar esta experiência (que lhes fora encarregada no princípio do ano letivo próximo passado pelo seu mestre, o doutor Domingos Vandelli) com a assistência do Excelentíssimo Reitor da Universidade, por esta razão se demorou até o referido tempo. E efetivamente no dia 27 assistiram à experiência o dito Excelentíssimo Reitor com todo o corpo acadêmico, nobreza e povo, por quem os autores dela foram geralmente aplaudidos. ${ }^{6}$

Vários outros experimentos semelhantes foram executados pelos entusiasmados alunos do Prof. Vandelli em outras ocasiões, tanto com balões de ar quente como de hidrogênio, como relata seguidamente a Gazeta de Lisboa. Aliás, a empolgação com os novos gases por pouco não leva a desastres irreparáveis. Por ocasião do casamento do Infante D. João, futuro D. João VI, mandou o Reitor que os alunos de Química fizessem uma iluminação espetacular de todo o pátio interno da Universidade de Coimbra com bicos de metal por onde ardiam chamas de hidrogênio. Pouco depois, para celebrar um aniversário Real, noticia a Gazeta uma proeza ainda mais temerária, que se fez em Coimbra em 1785: além da iluminação do costume se formou no terreiro da Universidade, defronte do Palácio, uma gruta, em que estava uma fonte perene de fogo, que ardeu das 7 até as 2 horas; eram mais de 150 chamas contínuas, todas com diversas direções; na parte superior se via uma águia lançando fogo pelo bico e pontas das asas, e na parte mais inferior duas grandes tulipas. A todos causou grande gosto e admiração o ver umas bocas dos tubos lançando as chamas para cima, a modo de repuxo, outras para baixo, por forma de cascata, as mais para um e outro lado: obra devida à invenção do sábio Doutor Vandelli. ${ }^{7}$ Considerando a enorme quantidade de hidrogênio queimado por 7 horas, foi um milagre que a Universidade tivesse saído ilesa de um experimento que seguramente nenhum químico de hoje ousaria empreender.

Na segunda metade do século XVIII fundaram-se no Rio de Janeiro, sob a égide de Vice-Reis sucessivos, o Marquês do Lavradio (1769-1778) e D. Luís de Vasconcelos e Sousa (1778-1790), duas associações que tinham por finalidade o cultivo e a disseminação das ciências, emulando as academias que proliferavam na Europa. Foram elas, respectivamente, a Academia Científica, que existiu de 1772 a 1778, e a Sociedade Literária do Rio de Janeiro, de 1786 a 1794. Infelizmente as duas associações tiveram existência fugaz e não alcançaram o papel que pretendiam de propulsoras do desenvolvimento científico. Todavia, elas foram bastante interessantes ao retratar por suas discussões e publicações a forma como vinham até o Brasil as cogitações científicas que agitavam o velho continente, e como reagiam a esses progressos os brasileiros que tinham acesso ao conhecimento. Só se tratará aqui da Sociedade Literária do Rio de Janeiro. Esta teve a honra de ganhar a dedicatória de um importante livro, os Elementos de Chimica, ${ }^{8}$ publicado em Coimbra em duas partes, em 1788 e 1790, por Vicente Coelho de Seabra Silva Telles, brasileiro de Congonhas do Campo, Capitania de Minas Gerais. O livro deveria servir, como se lê em seu frontispício, para ser usado no curso de Química que, aparentemente, a Sociedade pretendia estabelecer. Infelizmente, este curso jamais se materializou. Todavia, durante algum tempo a Sociedade funcionou de forma mais ou menos regular, reunindo-se uma noite por semana, em reuniões em que os sócios liam comunicações diversas, que eram então discutidas pelos demais, assim como numa sociedade científica moderna. O sócio João Manso Pereira viria a descrever uma dessas sessões em seu livro Memoria sobre uma nova Construcção do Alambique, ${ }^{9,10}$ publicado em 1805. O livro é uma tradução muito comentada de uma obra do francês Abbé Rosier, com a indicação no subtítulo de ter sido traduzido pelo P. J. P de A., que provavelmente significa Prof. José Pinto de Azeredo. Em uma longa nota de rodapé nas páginas 35-36, João Manso também descreve vários experimentos com gases feitos na Sociedade pelo Dr. José Pinto de Azeredo, agora com o nome dado por extenso. O Dr. Azeredo era um médico carioca que havia estudado na Universidade de Edimburgo, onde fora aluno de Joseph Black, o descobridor do dióxido de carbono. O título de Professor se devia a que o Dr. Azeredo havia sido nomeado professor da Escola de Medicina recém-fundada em Angola, para onde ele se dirigiria pouco depois. Ademais, os médicos costumavam ser chamados de professores.

Azeredo é uma dessas figuras quase esquecidas pela História. Ele mereceu, contudo, um alentado estudo recentemente, que trata de estabelecer seu papel na História da Ciência e da Medicina LusoBrasileira da segunda metade do século XVIII ao início do século XIX. Este estudo tem grande importância ao mostrá-lo como a primeira pessoa no mundo lusófono, e certamente um dos primeiros em qualquer parte, a investigar a Química da atmosfera com uma preocupação nitidamente ambiental, tornando-o claramente interessante para nosso mundo contemporâneo. ${ }^{11}$

José Pinto de Azeredo nasceu no Rio de Janeiro, provavelmente em 1763 ou 1766. Ele fez seus estudos preparatórios com o professor e poeta Manuel Inácio da Silva Alvarenga, o futuro condutor da Sociedade Literária do Rio de Janeiro e autor de seus estatutos. Ele e seu irmão mais novo Francisco Joaquim de Azeredo se matriculam na Faculdade de Medicina da Universidade de Edimburgo em 1786. Na capital da Escócia, entre outros escritos, José redige uma memória sobre os efeitos do ar fixo sobre o sistema nervoso.

Ele logrou ganhar em 1788 um prêmio atribuído todo ano ao melhor trabalho dos finalistas do curso de Medicina pela Harveian Society of Edinburgh. ${ }^{11}$ Com isto, foi também nomeado por um ano para presidir a Medical Society of Edinburgh.${ }^{11}$ A partir de Edimburgo os irmãos foram para Leiden, a fim de ultimar seus doutorados naquela universidade holandesa de tão grande prestígio na Medicina. José defendeu sua tese em 24 de maio de 1788, apresentando uma dissertação sobre a gota.

Após o retorno a Portugal, José Pinto de Azeredo foi nomeado pela Rainha D. Maria I físico-mor de Luanda, Angola. Lá ele ainda teria como tarefa instalar e dirigir a recém-criada Escola de Medicina de Luanda, e que efetivamente se materializou. Seu trabalho em Luanda duraria até 1797, quando retornou a Portugal, onde viria a falecer em 1810, em Lisboa. Antes de ir para Angola, contudo, Azeredo passou cerca de um ano no Brasil, de 1789 a 1790, num aprendizado de doenças tropicais na Bahia, no Rio de Janeiro e em Pernambuco. Foi nesse período que ele participou das reuniões da Sociedade Literária a que João Manso Pereira se refere.

Em março de 1790, Azeredo publicou no Jornal Enciclopédico de Lisboa, periódico voltado para as ciências e dirigido pelo médico, farmacêutico e químico Manoel Joaquim Henriques de Paiva, um longo artigo de 30 páginas intitulado Exame quimico da atmosphera do Rio de Janeiro, Feito por Jozé Pinto de Azevedo (sic), doutor em Medicina pela Universidade de Leide, Fisico mór, e Professor de Medicina do Reino de Angola, etc. ${ }^{12}$

Ao introduzir o assunto, Azeredo descreve sucintamente o papel de vários filósofos naturais no progresso da ciência química no século XVIII, sem, contudo, incluir Lavoisier, que só mais tarde aparece em outros trechos do artigo. Entre aqueles citados por seu papel nos estudos da atmosfera estão os suecos Bergman e Scheele, o escocês Black, os ingleses Priestley e Cavendish, o holandês Ingenhousz e o francês Macquer. Veja-se o que ele afirma: Estes filósofos entraram a examinar mais profundamente a nossa atmosfera; acharam que além dos vapores e partículas heterogêneas contém um fluido elástico, que em todos os tempos, e em todos os lugares é composto de três substâncias mui diferentes entre si. Estas substâncias separadas produzem diversos efeitos sobre os corpos organizados. Uma parte, que lhe chamaremos ar puro (a) é própria e necessária para a respiração 
e para o fogo. A segunda, que chamaremos ar fixo (b), sufoca aos animais, a destrói toda a irritabilidade (sic). A terceira, que chamaremos ar mofete (c), é de uma natureza inteiramente desconhecida. É sim imprópria para a respiração e combustão, destrói a vida dos animais; porém não precipita a cal, nem é absorvido pela água. ${ }^{13}$

Logo a seguir ele contrasta a química flogística pré-lavoisiana com a explicação dada pelo químico francês ao descrever a combustão como uma reação com o oxigênio: $M r$. Lavoisier, examinando o fenômeno mui atentamente explicou de um modo mais filosófico. ${ }^{14}$ Ao dar razão à interpretação de Lavoisier do papel do oxigênio nas oxidações, acrescenta: Concedendo nós este fato de Mr. Lavoisier, acho fácil dar a razão porque unindo nós o ar nitroso (óxido nítrico, NO) com o ar puro, fique toda a composição de uma cor vermelha, $e$ seja logo absorvida pela água. Esta, provada, tem o mesmo gosto que o ácido nitroso (ácido nítrico) diluído. Por cuja razão é o ar nitroso o melhor meio que temos para conhecer a pureza do ar; e dele é que me servi nas experiências seguintes..$^{15}$

A seguir vem uma extensa descrição dos experimentos levados a cabo no Rio de Janeiro para determinar a pureza do ar em diferentes sítios da cidade:

\section{Experiência $1^{a}$}

Em um tubo de vidro dividido em partes iguais introduzi tanto ar da Prainha quanto enchesse 16 partes: depois introduzi no mesmo tubo uma porção de ar nitroso igual a uma parte. Toda a composição se fez vermelha, e a água subiu uma parte. Introduzi segunda porção; o efeito foi o mesmo: introduzi terceira, a mudança de cor apenas se percebeu, e a água subiu três partes, $e^{1 / 2}$ da quarta. ${ }^{15}$

$\mathrm{O}$ experimento de Azeredo consistia em reagir o óxido nítrico incolor (chamado por ele de ar nitroso) com o oxigênio contido no ar, produzindo o gás vermelho-acastanhado dióxido de nitrogênio, o qual reage com a água dando ácido nítrico (em sua nomenclatura, ácido nitroso, como se lê em outros trechos), o que faz desaparecer a cor. À medida que mais óxido nítrico ia sendo introduzido, menos intensa era a reação, uma vez que o teor de oxigênio no ar do tubo diminuía. Ele repetiu este procedimento em sítios distintos da cidade: Prainha, São Francisco de Paula, Misericórdia, Passeio Público e seus arredores até a Glória, e os Morros de São Bento, do Colégio (Morro do Castelo), da Conceição e de Santo Antônio.

De seus experimentos conclui Azeredo que uma porção de ar da nossa atmosfera, dividida em 16 partes, contém $3 / 16+1 / 2$ de ar puro; o que vem a ser menos do que o que é comumente na Europa, que segundo as experiências de Bergman e Mr. Lavoisier, o ar puro sempre chega a $1 / 4$ de uma porção dada. ${ }^{16}$

Aqui é necessário fazer uma interpretação de seus dados. O que ele quer dizer provavelmente é que o teor de oxigênio no ar é de 3/16 mais metade de $1 / 16$, ou seja, $21,9 \%$. Seu valor está então muito mais próximo do valor real de cerca de $21 \%$ que aquele que ele cita como sendo o dos químicos europeus.

É bastante curioso assinalar que ele consegue resultados tão bons usando em parte uma Química lavoisiana, mas que, em termos de teoria, ainda claudica entre esta e a velha Química do flogisto, tão duramente combatida por Lavoisier, como denodadamente defendida por Priestley. Assim, ao discorrer sobre a parte boa do ar, ou seja, o oxigênio, diz ele: Esta mesma porção é tão necessária aos homens e animais quanto é a mesma respiração. Porque como os nossos bofes lançam continuamente muita quantia de flogisto, era necessário que houvesse uma substância que, combinando-se com ele, separasse uma matéria nociva. $O$ ar puro que é o único que tem atração por flogisto, em tocando os nossos bofes se converte imediatamente em ar fixo, como vemos evidentemente se respirarmos por um tubo dentro d'água de cal. ${ }^{17}$

Azeredo conclui que o melhor local da cidade em termos da pureza do ar, ou seja, do teor de oxigênio, é o Passeio Público, o jardim recém-inaugurado pelo Vice-Rei D. Luís de Vasconcelos. A ele se seguem os ares dos vários morros da cidade. A pior qualidade de ar está na Misericórdia, e ele dá a razão: Pode ser que os vapores corruptos do hospital imediato, e dos quarteis sejam a causa desta diminuiçào do ar puro. ${ }^{18}$

Após a determinação do teor de oxigênio ele passa a estudar a participação do dióxido de carbono na atmosfera do Rio de Janeiro. A maneira de determinar o teor de dióxido de carbono no ar consistia em adicionar água de cal (solução diluída de hidróxido de cálcio) ao ar contido num tubo, e verificar a subida do nível da solução após a absorção do gás carbônico e consequente precipitação de carbonato de cálcio. Segundo suas determinações, o ar do centro da cidade tinha o maior teor de gás carbônico. Todavia, ele concluiu que o percentual desse gás na atmosfera do Rio, sempre abaixo de 1/16 do total, era bem inferior àquele encontrado geralmente na Europa: podemos concluir que a quantidade de ar fixo na nossa atmosfera é menor que na Europa, que nunca é menos de 1/16. Os contínuos fogos nos climas do Norte, durante o inverno, fazem grande parte do ar puro converter-se em fixo. As contínuas neves sobre os campos, a decadência das folhas das árvores, a falta da impressão da luz sobre os vegetais proíbe que estes absorvam o ar impuro e lancem o ar deflogístico (oxigênio). Estas razões eram bastantes para que houvesse maior quantidade de ar fixo nesses climas que nos nossos. ${ }^{19}$

$\mathrm{O}$ trabalho de Azeredo é de uma grande atualidade nestes tempos de preocupação ambiental, não apenas pelo assunto em si como por total pioneirismo e originalidade na área demonstrada por ele. Certamente ele foi o primeiro a determinar experimentalmente as características químicas do ar de qualquer localidade no hemisfério ocidental, mas também aparece como um dos primeiros em todo o mundo a pôr a Química a serviço da determinação da qualidade do ar respirado pela população de uma cidade.

A química atmosférica era de grande atualidade no início do século XIX, e sua importância foi demonstrada de forma espetacular logo nos primeiros anos do século.

Uma investigação de grande consequência para os estudos da atmosfera e para toda a ciência foi levada a cabo em 1804 pelo químico francês Louis-Joseph Gay-Lussac (1778-1850). Ele fez duas ascensões em balão naquele ano. A primeira foi realizada no dia 24 de agosto, em companhia do físico Jean-Baptiste Biot (1774-1862). Os dois fizeram vários experimentos físicos, mas Gay-Lussac desejava muito mais; desta maneira, pouco mais de um mês depois da primeira ascensão, em 16 de setembro, ele empreendeu um segundo voo, desta vez sozinho, que atingiu $7016 \mathrm{~m}$ acima do nível do mar, marca que só seria superada em 1850 , ano de sua morte. ${ }^{20}$ Entre os vários experimentos conduzidos, de Física, Química e Fisiologia, ele estava particularmente interessado em elucidar uma dúvida que atormentava muitos químicos da época: uma vez que os gases constituintes da atmosfera terrestre têm pesos diferentes, não haveria uma concentração maior dos gases mais pesados nas camadas inferiores, de modo que a composição da atmosfera variasse com a altitude, assim como varia a pressão total? Gay Lussac fez a ascensão munido de dois tubos evacuados que foram abertos acima de $6000 \mathrm{~m}$ de altitude e, em seguida, fechados. Após a descida, ele analisou o teor de oxigênio nas duas amostras de ar e verificou que ele coincidia com o teor observado na superfície. ${ }^{20} \mathrm{~A}$ determinação experimental da constância da composição da atmosfera teve consequências importantíssimas, pois permitiu a John Dalton validar com segurança sua Lei das Pressões Parciais, a qual foi fundamental para a elaboração de sua Teoria Atômica poucos anos depois, em 1807. ${ }^{21}$

No Brasil se travaria um importante debate sobre a Química atmosférica na década de 1850 . Ao contrário do que sucedia à época de José Pinto de Azeredo, porém, desta vez a questão não seria baseada em resultados experimentais, mas em argumentação 
puramente dialética, em virtude da complexidade do assunto, de que seus protagonistas não suspeitavam.

Em meados do século, estava claro para os intelectuais da elite política que o país deveria depender cada vez menos da mão de obra escrava. A pressão econômica da Inglaterra, aliada ao desenvolvimento rápido e vigoroso da ciência e das técnicas na Europa, motivavam o pensamento de uma modernidade também intelectual e científica. Nesse espírito nasce a Sociedade Vellosiana de Ciências Naturais do Rio de Janeiro, da qual Alexandre Antonio Vandelli (1784-1862), filho do velho professor de Química e História Natural de Coimbra, Domingos Agostinho Vandelli (1735-1816), foi um dos sócios fundadores. A vida e a obra do segundo Vandelli já foram relatados num artigo publicado em Química Nova..$^{22}$ No presente trabalho será discutido apenas seu papel pontual no debate apresentado mais adiante. A Sociedade Vellosiana foi criada oficialmente em 17 de setembro de 1850 com a finalidade, segundo o artigo $1^{\circ}$ de seus Estatutos, de indagar, coligir e estudar todos os objetos pertencentes à História Natural do Brasil; e juntamente averiguar e interpretar as palavras indígenas com que forem designados. ${ }^{23}$

A partir dessa premissa estatutária, oriunda da necessidade de uma modernização científica do país, Alexandre Vandelli, o botânico Francisco Freire Allemão de Cysneiros (1797-1874) e outros fundadores desejaram incentivar a pesquisa de temas científicos eminentemente nacionais. $\mathrm{O}$ nome da instituição, sugerido por Freire Allemão, foi uma homenagem ao naturalista Frei José Mariano da Conceição Veloso (1742-1811). Autor da importante obra de botânica Flora Fluminensis, que expõe o resultado de suas investigações científicas realizadas na Província do Rio de Janeiro durante 8 anos, Frei Veloso foi motivo de inspiração para os naturalistas de sua época. É importante ressaltar neste momento histórico o nome de Freire Allemão. Personagem de escol na ciência brasileira, filho de um lavrador, tornou-se médico de D. Pedro II e professor de Zoologia. Estudou na Academia de Medicina da Universidade de Coimbra, local onde obteve o diploma de cirurgião. Defendeu sua tese na França em 1828, onde se graduou Doutor em Medicina. Voltou para o Brasil em 1832 e no ano seguinte obteve a cátedra de Botânica e Geologia da Escola de Medicina do Rio de Janeiro. Foi o pioneiro na avaliação do grave problema do bócio endêmico no Brasil, observando populações de Minas Gerais. Membro do Instituto Histórico e Geográfico, autor de dezenas de publicações e pranchas sobre plantas brasileiras, descreveu várias plantas ainda desconhecidas. ${ }^{24}$

Freire Allemão integraria a Comissão Científica que fez a exploração do Ceará, sendo o presidente e chefe da seção botânica da Comissão (1859-1861), proposta pelo Instituto Histórico e Geográfico Brasileiro. Composta de naturalistas e engenheiros, ela tinha o objetivo de explorar cientificamente as províncias do norte e nordeste do país. Esta Comissão, que ficou conhecida depreciativamente como Comissão das Borboletas, deixaria o Rio de Janeiro em janeiro de 1859, percorrendo as províncias do Ceará, Piauí, Pernambuco, Paraíba e Rio Grande do Norte. No Ceará seriam colhidas 20.000 amostras de plantas, e muitas delas, assim como instrumentos e outros materiais, foram incorporados ao acervo do Museu Nacional no Rio de Janeiro. ${ }^{24}$

Em 1866 ele seria nomeado Diretor do Museu Nacional, sucedendo a Frederico Burlamaque e ocupando o cargo até 1870. Em 1866, presidiria a comissão destinada ao estudo e classificação de vegetais para o pavilhão brasileiro na Exposição Universal, a realizarse em Paris no ano seguinte. A fitografia, a histologia e a fisiologia vegetal foram, por mais de meio século, objetos de seus estudos e descobertas, principalmente sobre as espécies vegetais do Brasil que eram geralmente enviados à Europa. Ele também foi um desenhista de alta qualidade, como o atestam seus esboços e pranchas. Freire Allemão descreveu inúmeras plantas novas, muitas das quais ainda conservam o nome que ele lhes deu, e nomeou numerosos gêneros, como visto nas Atas da Sociedade Vellosiana. ${ }^{24}$
Retornando à Sociedade Vellosiana, no início de seu funcionamento os sócios efetivos foram distribuídos em quatro seções, sendo estas consideradas permanentes: Etnografia, Zoologia, Botânica, Geologia e Ciências Físicas. ${ }^{25}$ Alexandre Vandelli chegou a exercer a Presidência ad hoc da Sociedade em 1850, assinando o diploma de Freire Allemão, apesar de em pouco tempo estarem em lados opostos nas discussões científicas. ${ }^{26}$

A Sociedade passou por muitos problemas ao longo de sua história, com inúmeras dissensões internas e ressentindo-se da falta de participação e apoio do Imperador D. Pedro II. O Imperador foi assíduo frequentador de reuniões intelectuais e científicas, como as do Instituto Histórico e Geográfico Brasileiro, nunca prestigiando, porém, os encontros da Sociedade Velosiana. As divergências internas resultaram no adormecimento contínuo e gradual da instituição. Apesar de o fim das atividades normalmente ser apontado como o ano de 1852, os registros das Atas do Arquivo do Museu Nacional e do Almanak Laemmert mencionam reuniões esporádicas até 1857 , seguindo-se posteriormente atas de outros encontros até pelo menos $1871 .^{27}$

Alexandre Vandelli é o autor de um documento de enorme interesse e importância que retrata bem os debates ocorridos nas reuniões da Sociedade Velosiana. Este longo documento nunca foi publicado, encontrandose em forma manuscrita no Arquivo do Museu Imperial de Petrópolis. Ele se intitula Reflexão sobre a questão dos nevoeiros seccos da atmosfera do Rio de Janeiro. Apresentada na Sociedade Vellosiana, pelo Snr. Dr. Francisco Freire Allemão ${ }^{28}$ Neste manuscrito Vandelli procura rebater as propostas de Francisco Freire Allemão de Cysneiros (principalmente) e de Frederico Leopoldo César Burlamaque a respeito da origem dos nevoeiros secos que costumavam cobrir o Rio de Janeiro, sobretudo entre agosto e setembro. O manuscrito foi presenteado por Vandelli a D. Pedro II, e compõe-se de três partes, datadas de 16 de abril, 24 de novembro e 10 de dezembro de 1853 , respectivamente. São ao todo 41 páginas manuscritas em letra uniforme e legível, muito diferente da grafia original de Alexandre Vandelli. A terceira parte é intitulada Aditamento, tendo sido composta após a carta de dedicação ao Imperador. ${ }^{28} \mathrm{~A}$ carta de leitura difícil de Alexandre Vandelli a D. Pedro II já mostra o espírito da querela entre os debatedores, ou ao menos o espírito crítico de sua parte:

\section{Senhor.}

A questão dos Nevoeiros seccos da extincta Sociedade Velosiana, que V.M.I. estou certo, não deixou passar desapercebida, não deixa pelo menos de incutir curiosidade. Não podendo pubblicar as

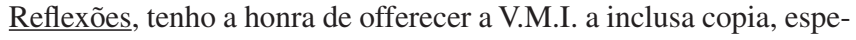
rando que V.M.I. se digne aceitar; e ficarei muito satisfeito do meu insignificante trabalho, se merecer por hum momento a Sua Augusta attenção: em cujo caso farei apromptar a copia da sua continuação.

Neste insignificante trabalho, só me pertence a especificação(?) do phenomeno, o que, comtudo, os outros não fizerão: e só transcrevo os aucthores (ilegível) em que me fundo, porque as sciencias da observação, e exactas são diferentes da poezia, e não admittem como esta divagações e fantasias para encher com palavras a escassez de assumpto ou materia.

Beija a Augusta Mão de V.M.I. com todo o respeito e submissão,

Rio de Janeiro 13 de Nov. de 1853

$\mathrm{O}$ rev ${ }^{\text {te }} \mathrm{e} \mathrm{ob}^{\mathrm{mo}}$ subdito

Alexandre Antonio Vandelli ${ }^{28}$

A querela de Vandelli com seus consócios iniciou-se quando Freire Allemão colocou o tema em debate na Sociedade Vellosiana, em 25 de setembro de 1851. Ocorreu através das Questões propostas para serem discutidas por escripto. Textualmente, as questões foram:

$1^{o}$ - O denso nevoeiro, ou o enfumaçado da atmosfera do Rio de Janeiro, e de quase toda, senão toda a costa do Brasil nos meses de 
julho a outubro será devido a uma evaporação terrestre, ou vulcânica, como pensou Sanches Dorta? Ou será devido a queimadas como se acredita vulgarmente?

$2^{\circ}$ - Se este fenômeno é devido às queimadas, datará ele de tempo anterior à conquista?

$3^{\circ}$ - Se é anterior às conquistas; seriam estas queimadas puramente acidentais, como pensam alguns, ou eram de proposito feitas pelos selvagens, como sustentam outros? E então por que motivo o fariam?

$4^{o}$ - Provada e existência dos incêndios nos tempos dos selvagens, casuais, ou não, foram eles (os incêndios) que produziram os maçagais, ou campos, pela destruição das matas, como é opinião de Volney e outras pessoas; ou pelo contrário os incêndios pressupõem a existência de campos naturais ${ }^{24}$

Atualmente sabe-se que a passagem da luz solar (ou lunar) pela atmosfera carregada de grãos (que podem ser oriundos das queimadas ou mesmo da poluição das grandes cidades) provoca o avermelhamento da luminosidade celeste. É um fenômeno comum, sobretudo no inverno e próximo da linha de visada do horizonte. No caso do Brasil ocorrem principalmente nos meses de inverno (exatamente a época observada por Freire Allemão), quando as camadas da atmosfera próximas ao solo estão mais frias e, portanto, mais densas. Tal propriedade é reforçada pela menor convecção atmosférica nos meses mais frios. ${ }^{27}$

Fisicamente o que ocorre é que a luz branca solar sofre espalhamento elástico na atmosfera terrestre, espalhando preferencialmente a luz azul de maior frequência (menor comprimento de onda) ao interagir com os gases que a compõem. Por isso o céu terrestre é azul. ${ }^{29}$ Os grãos de poeira em suspensão espalham a luz visível em forma de luz com menor frequência (apresentando comprimentos de onda maiores, isto é, do amarelo ao vermelho). O horizonte ou partes do céu ficam com uma coloração avermelhada. Este é um dos componentes da chamada névoa seca dos meteorologistas.

Após as quatro questões, Freire Allemão busca explicar sua hipótese. A primeira autoridade na qual Freire Allemão se apoia são as observações do astrônomo português Bento Sanches Dorta (1739-1795), realizadas entre os anos de 1781 e 1788. Dorta realizara no Rio de Janeiro muitas observações da altura do Sol e de eclipses dos satélites de Júpiter com o fim de determinar as coordenadas geográficas da cidade, e percebera a existência das névoas em 1784. As observações de Sanches Dorta são o prelúdio da cultura astronômica na cidade, muito antes do Imperial Observatório Astronômico fundado por D. Pedro I em 1827. As observações de Sanches Dorta foram publicadas nos tomos I e III das Memórias da Academia das Ciências de Lisboa (1797 e 1812).

Freire Allemão foi acometido por uma dúvida, principalmente em virtude de a observação do fenômeno dos nevoeiros secos por Sanches Dorta ter ocorrido no mês de abril de 1784, e não no segundo semestre como ocorria em sua época. Discorrendo a seguir sobre o fato, ele supõe plausível a hipótese de Sanches Dorta: a de que em outros locais a névoa também surgia, tais como em Nova York, Orléans, Berlim, Sibéria, Calábria, Islândia. As névoas poderiam ser, em certos casos, decorrentes de vulcões ou fumaça oriunda de fendas no solo, principalmente após a incidência de terremotos como havia ocorrido na Europa entre o final do século XVIII e o primeiro terço do século XIX.

Contudo, a opinião final de Freire Allemão, centrando-se na cidade do Rio de Janeiro, foi atribuir o fenômeno às queimadas. Ele havia observado em 1816 no interior fluminense, estando próximo a queimadas, um resultado muito semelhante de avermelhamento do céu. Para Freire Allemão era o mesmo tipo de névoa que cobria o Rio de Janeiro na época da discussão na Sociedade Velosiana. Assim como acontecia na Holanda ou no norte da Alemanha com a queima de carvão, os nevoeiros secos tornavam o céu turvo, com uma faixa de cor rubra, tirando para o escuro. Ele afirma ainda que a sombra dos objetos terrestres se torna imperfeita. A associação com o fenômeno naqueles países o convence de que essa era a melhor explicação para o caso.

Sessenta anos depois de Azeredo, na época da Sociedade Velosiana, a proposta de Freire Allemão seria a mais viável entre as que surgiram e serão aqui apresentadas. É importante ressaltar que Freire Allemão recorre em seu primeiro texto a observações ocorridas no final do século XVIII, contemporâneas, portanto, de Azeredo, para justificar sua atribuição das queimadas como causadoras dos nevoeiros secos. ${ }^{27}$

Frederico Leopoldo César Burlamaque (1803-1866), engenheiro e matemático, foi professor de matemática na Escola Central. Ele havia derrotado Alexandre Vandelli quando ambos concorreram ao cargo de diretor do Museu Nacional, em 1847. Burlamaque dirigiu o museu daquela data até 1866. Ele apresentou na Sociedade Vellosiana, em 06 de outubro de 1851, outra proposta sobre o problema dos nevoeiros secos, intitulada Qual é a causa do enfumaçamento da atmosfera do Rio de Janeiro em certa época do ano? - Questão esta que se reduz à seguinte: - Qual é a causa dos nevoeiros secos? ${ }^{24}$

A partir da argumentação de Freire Allemão, Burlamaque considerou o assunto tão difícil de resolver quanto o dos aerólitos, das estrelas cadentes, ou mesmo dos nevoeiros que cobrem os mares polares. Para ele, efeitos idênticos devem ter causas idênticas, ou seja, a causa deveria ser a mesma em todos os lugares do mundo (citados por Freire Allemão), mesmo respeitando as circunstâncias locais. Para Burlamaque, atribuir os nevoeiros secos às queimadas não poderia explicar todas as observações e a maneira como ocorriam, considerando ele a quantidade de queimadas insuficiente para provocar algo daquela magnitude. Se as causas fossem as queimadas, o fenômeno deveria incluir também uma nítida chuva de cinzas ou a presença de um forte cheiro de fumaça, e nenhum dos efeitos era observado no Rio de Janeiro.

Burlamaque percebe que a época de ocorrência dos nevoeiros era sempre próxima do equinócio de setembro, e coloca acertadamente a pergunta: Terá a mudança de estação alguma influência sobre o aparecimento deste fenômeno $?^{24}$ Esta é a resposta para ele, pois parece-lhe a mais plausível de todas. Para balizar sua proposição, cita Alexander von Humboldt (1769-1859), que atribui as névoas secas ao movimento de aproximação ou afastamento do sol em relação ao equador. A partir de uma informação do próprio Freire Allemão, de que ocorriam queimadas em regiões do Rio de Janeiro no verão e que nem por isso as névoas secas são vistas na cidade na ocasião, Burlamaque argumentou que se o fenômeno fosse devido apenas à queima vegetal ou mineral, haveria uma constante névoa densa e negra sobre as cidades. Isso, porém, não ocorria. Usa como exemplo Londres e a imensa quantidade de carvão queimada naquela cidade para aquecimento no inverno. Apesar da enorme quantidade de carvão usado para aquecimento e para mover as indústrias inglesas, a névoa local era normalmente branca e úmida, sendo conhecida na GrãBretanha desde seus primórdios. No entanto, aparentemente sem o conhecimento de Burlamaque, a partir do século XIX Londres passou a ser coberta pelo fog, uma densa névoa escura, que só desapareceu nos anos 1970, quando todo o carvão de aquecimento passou a ser tratado para eliminar o enxofre.

Seguindo em seu texto, acabou Burlamaque por citar outras hipóteses geralmente mencionadas por outros autores para o caso em estudo: vapores do calor central da Terra; a imersão da atmosfera na cauda de um cometa; fumo exalado das erupções vulcânicas; fumo de 
um corpo estranho que se teria queimado sem chama; pó impalpável produzido pelo fim de um planeta consumido por seu fogo central; ou ainda pelo encontro de um cometa. Propôs ainda que houvesse possíveis efeitos elétricos, os quais ele não explica.

Para o Diretor do Museu Nacional, contudo, muitas das causas mencionadas por seus pares mostravam-se pouco satisfatórias. O generalismo na ciência não fazia sentido para Burlamaque. Ele não acreditava em causas exógenas para o fenômeno: atribuir a causas estranhas ao nosso globo a origem de certos fenômenos que nele se passam é recorrer a atos de imaginação, é forjar hipóteses mais ou menos plausíveis, que de ordinário não satisfazem ao espírito, ou não resistem a um frio exame. ${ }^{24}$

Explicações inerentes aos processos internos do planeta, como tremores ou vulcões, também não se mostravam viáveis. São fenômenos longínquos à realidade brasileira, além de muito grandiosos para provocar um efeito demasiado pequeno. Continua Burlamaque em sua argumentação:

se os nevoeiros secos de 1783 e 1834 podem ser atribuídos a causas estranhas ao nosso globo, eles deveriam ter sido muito mais gerais, e em muito maior escala do que realmente não foram, e portanto de nenhum modo podem servir para explicar fenômenos locais e muito parciais, particularmente os que periodicamente aparecem nos países intertropicais. ${ }^{24}$

Ao finalizar suas reflexões, Burlamaque mostra coerência em seus argumentos. Sua explicação é a mais correta entre os debatedores, feita inclusive a partir das observações daquele ano, quando as névoas foram particularmente intensas, tanto as secas quanto as úmidas. $\mathrm{O}$ fato de ter havido poucos ventos acabou por concentrar ainda mais os nevoeiros sobre a cidade, tornando a visão ainda mais difícil à distância. O efeito avermelhado do sol e da lua se mostrara inalterado nas ocasiões em que os astros foram vistos no horizonte. Lendo suas explicações verifica-se que ele tende a relacionar as névoas com a estação do ano no Rio de Janeiro, ou seja, com o inverno. Faltava a Burlamaque apenas conhecer a questão das inversões térmicas na atmosfera.

Em primeiro de outubro de 1852, Freire Allemão apresenta uma réplica à argumentação de Burlamaque na Sociedade Velosiana: Questão do nevoeiro, ou enfumaçado da atmosphera do Rio de Janeiro. (Replica). ${ }^{30}$ Diz que escreveu apressadamente suas propostas, e que as mesmas foram tomadas à frente pelo talento de Burlamaque. Insistiu Freire Allemão, apesar de seu consócio ter diferenciado as névoas secas das queimadas, que estas seriam as verdadeiras causas dos nevoeiros. Freire Allemão ressalta uma passagem na qual foi explicitada que a quantidade observada de fumo levantada em determinada explosão vulcânica foi suficiente para cobrir, na Europa, muitas vilas. E questiona o caso da Inglaterra citado por Burlamaque, já que deveriam ser levadas em consideração questões atmosféricas de cada cidade. Assim, o cheiro das queimadas poderia não ser percebido depois de alguma distância devido a vários fatores locais

Reafirmando que a causa devia ser apenas a fumaça, termina sua réplica afirmando que eram comuns as queimadas também em outras províncias, como Minas Gerais, não descartando que também ocorresse no Rio de Janeiro a mistura da névoa seca com verdadeiro meteoro. Ou seja, não descartava a presença de fenômenos astronômicos na alteração atmosférica que se apresentava.

Contrariando os dois textos de Freire Allemão, assim como aquele de Burlamaque, todos apresentados na Sociedade Vellosiana, Alexandre Vandelli propôs, em seu manuscrito de 1853, que as névoas seriam relacionadas a fenômenos atmosféricos e astronômicos. Era uma explicação diferente, apesar de ainda em voga na época, de que era possível e constante a influência cósmica na atmosfera terrestre. ${ }^{28}$ No material de estudos astronômicos de D. Pedro II, por exemplo, depositado no Arquivo do Museu Imperial de Petrópolis, há um pequeno texto anotado em letra cursiva no qual o Imperador se ocupa em estudar os nevoeiros relacionados a material astronômico e de erupções próximas à Calábria no ano de 1783. Eles haviam sido registrados e investigados pelo naturalista alemão Johann Reinhold Forster (1729-1798).

Ao longo de seu trabalho Alexandre Vandelli atacou de forma virulenta seus dois debatedores, deixando claras as desavenças que ocorriam no interior da Sociedade Velosiana e que certamente contribuíram para o fim desta. O que possivelmente também contribuiu para as querelas entre Vandelli e os outros dois naturalistas envolvidos na questão dos nevoeiros secos, estes amigos entre si, foi a antiga disputa de Vandelli com Burlamaque pelo cargo de Diretor do Museu Nacional. ${ }^{31}$

Alexandre Vandelli combateu tanto a argumentação de Francisco Freire Alemão como a de Frederico Leopoldo César Burlamaque, apresentadas na Sociedade Velosiana, a respeito do aparecimento de nevoeiros secos no Rio de Janeiro nos meses de inverno. Como descrito anteriormente, tanto Freire Alemão como Burlamaque concordavam que o fenômeno consistia num denso nevoeiro, ou enfumaçamento da atmosfera do Rio de Janeiro, e de quase toda, senão toda a costa do Brasil nos meses de julho a outubro. ${ }^{32}$ Frederico Burlamaque percebeu que o fenômeno ocorria em diferentes partes do globo, logo, sua explicação não deveria ater-se a um fenômeno local como as queimadas; o fenômeno poderia ser observado, às vezes, até em alto mar. Alexandre Vandelli discordará deste último ponto, dizendo que o fenômeno desaparece logo que nos afastamos da costa.

Burlamaque também não acreditava em causas exógenas para o fenômeno, não aceitando que os nevoeiros secos fossem um fenômeno extraterrestre, como viria a defender Vandelli. Este, que defendia a origem extraterrestre dos nevoeiros, chegou a escrever em tom de falsa modéstia e ironia: a velhice, ou decrepitude, com o seu horrível cortejo, e tanto pior, acompanhada com inumeráveis afecções morais, enfraquece, até totalmente extingue as faculdades mentais. Neste caso talvez eu já esteja, e será por esta razão que não dou a devida inteligência, compreendo mal o que refere o Sr. Dr. Burlamaque... O ensino antigamente embrutecia em vez de instruir; por isto, e pelas erradas doutrinas que me transmitiram, julgo de diferente modo, $e$ compreendo mal. ${ }^{28}$

Para Vandelli, não obstante sua fraca e cansada inteligência, aqueles nevoeiros não se limitavam às regiões intertropicais, mas estendiam-se da costa da África por toda a Europa, de Portugal à Sibéria, da Suécia ao Sul da França. Chamou em seu favor argumentos semelhantes, como os do francês Marcel de Serres, que é citado frequentemente. Freire Alemão opunha-se a Burlamaque, porém de forma inadequada e errônea, segundo Vandelli. Para Freire Alemão seria conveniente começar a discussão examinando se os nevoeiros secos não seriam devidos a fumos de queimadas, opinando que é importante saber-se em que a névoa seca se distingue dos fumos. ${ }^{35}$ Esta simples sugestão provoca a ira de Vandelli, que comenta ironicamente: sinto que escapasse isto ao Sr. Dr. Freire. Não se sabe o que é fumo, o que é névoa, e propõe-se a questão? Não é preciso abrir dicionário algum de história natural para dar a definição; basta saber ver, e ter idéias exatas das coisas, que são tão comuns como estas de que se trata. ${ }^{28}$

Alexandre Vandelli contrapõe em seus argumentos que os nevoeiros secos duravam por vezes de 30 a 40 dias, o que não seria próprio dos fumos, que se dissipavam rapidamente. Cunhou a frase de efeito que todas as esperanças loucas ou malfundadas desvanecemse, duram como o fumo. Argumentou ainda que o nevoeiro úmido fosse passageiro, durando apenas algumas horas, ou no máximo de um a dois dias.

Outra característica importante para Vandelli dizia respeito ao fato de os nevoeiros secos não tenderem a subir muito na atmosfera, 
como os nevoeiros úmidos ou os fumos, mas sim de ficarem adstritos às camadas inferiores da mesma. Esta se afigura hoje como uma arguta observação, tal como as de Burlamaque, a respeito de uma característica comum em nuvens de poluição, oriundas do fenômeno de inversão térmica. ${ }^{33}$

Ainda segundo Vandelli, Freire Alemão tem a ousadia de propor que se substituísse o nome nevoeiro seco por fumaça. Caso se decidisse fazer isso, os brasileiros ficariam escarnecidos porque ou não conhecemos o fenômeno, e não o soubemos classificar, ou quisemos ter o pueril gosto de termos um fenômeno só nosso, e particular das incógnitas queimadas dos índios. ${ }^{30}$ Nas muitas vezes em que Vandelli argumentou contra a possível origem dos nevoeiros secos a partir de queimadas, ele só se referiu às queimadas provocadas pelos índios. Não menciona as enormes queimadas dos fazendeiros através da mão de obra escrava.

Em um trecho de grande violência contra as idéias de Freire Alemão, escreve Vandelli: Não há analogia alguma entre as nuvens de fumo das combustões, ou antes fusões vulcânicas, com a causada pelas fogueiras ou combustão vegetal, e muito menos ainda com os nevoeiros secos, em que não entra fumo algum. Custa a atinar com a comparação da combustão vulcânica, liquificando rochas, decompondo e expelindo gases, água fervente, fluidos, lavas, escórias, cinzas, como as das fogueiras, que contêm diminutas parcelas de hidrogênio, azoto e carbônio. Não é possível a comparação da combustão em grande profundidade no centro da terra, e às vezes com a grande altura e pressão da enorme massa das águas do mar, com a combustão simples ao ar livre! O Sr. Dr. Freire mesmo (apesar de servir-se deste argumento) não pode deixar de reconhecer, que não é valioso para o caso de que se trata. (...) Se o Sr. Dr. Freire involuntariamente perturbou (propondo a questão) a popular posse e tranqüilidade da fumaça setembrina, sabe (desprezando todas as razões) procurar remediar o mal que fez, e mantê-la na posse popular em que estava. Foi-lhe para isto necessário recorrer à cediça e já há muito esquecida e desprezada filosofia de Aristóteles com as suas qualidades ocultas, em virtude das quais as cousas são o que são, $e$ fora disto é inútil levar as indagações. ${ }^{28}$

Em sua detalhada análise das memórias de Burlamaque e Freire Allemão, apresentou Vandelli opinião contrária à ideia de que os nevoeiros secos pudessem ter algo a ver com erupções vulcânicas. Principalmente pelo fato de eles serem tão comuns no Brasil, onde não existem vulcões, como escreveu Burlamaque ao final de seu texto. A conclusão é a de que só restaria uma explicação plausível para a formação dos nevoeiros secos. Buscando contínuo apoio em Marcel de Serres ${ }^{34}$, diz ele: $O$ todo do sistema a que pertencemos resulta da condensação da matéria nebulosa, análoga à que existe em diferentes pontos das vastas regiões do espaço... os planetas terão assim passado pelos mesmos estados que presentemente toma a matéria nebulosa, quando sucessivamente forma as auroras boreais, estrelas errantes, aerólitos, e por fim os cometas. ${ }^{28}$

Mais adiante, Vandelli expõe sua conclusão de que o enfumaçamento é de origem celeste (astronômica) e não terrestre: se as auroras boreais, estrelas errantes, aerólitos, ou melhor uranólitos, por estarem sujeitos à lei da periodicidade, são tidos e considerados como resultando de uma mesma causa, impelidos pelos mesmos movimentos, e serem diferentes estados de condensação da matéria nebulosa: e estando os nevoeiros secos no mesmo caso de afinidade que entre si têm aqueles fenômenos, parece necessária conclusão considerá-los e classificá-los como fazendo parte de um desses estados transitórios de condensação por que passa a matéria nebulosa, que já o é do éter.

A mui importante circunstância da periodicidade, a que todos dão tanto peso e consideração, é, quanto a mim, uma forte razão contra a errada e desarrazoada idéia do fumo e das fogueiras, que nos obrigaria a considerar também como proveniente de fumo as estrelas errantes, etc.

Procurarei explicar-me melhor. Aparecendo os nevoeiros secos nas mesmas épocas ou períodos em que costumam aparecer as auroras boreais, estrelas errantes, etc., parecem ter com aqueles alguma afinidade; admitindo-se, como geralmente o está, que o éter, passando por diferentes estados de condensação, forma as nebulosas, auroras boreais, estrelas errantes, aerólitos, cometas e planetas, parece que os nevoeiros secos, que estão nas mesmas circunstâncias (por aparecerem nos mesmos períodos daqueles) são um estado transitório por que passa ou o éter, ou já a matéria nebulosa; em uma palavra, certo estado de condensação por que passa o éter, ou a matéria nebulosa, que é já um estado mais condensado do éter. Finalmente, (tal é minha proverbial condescendência) concordarei a custo, que seja fumo, mas fumo celeste ou atmosférico, e não terrestre, e de palhas e restolho, mas da combustão ou alteração por que passa o éter ou matéria elementar, ou nebulosa, quando muda de estado, quando se vai condensando. ${ }^{28}$

Apesar da insistência numa origem extraterrestre para os nevoeiros secos, uma vez que em muitos casos eles apareciam periodicamente, além de também ocorrerem simultaneamente em diferentes pontos do globo, Vandelli escreve várias vezes que esses fenômenos não se manifestam em mar alto, extinguindo-se à medida que nos distanciamos da costa. Contudo, não apresenta uma explicação para a inexistência do fenômeno em mar aberto.

Aos nossos olhos modernos os argumentos de Alexandre Vandelli são surpreendentes, especialmente quando ele considera que fenômenos tão diferentes como auroras, meteoritos, cometas, planetas e nevoeiros secos constituam uma única classe de fenômenos, todos eles resultando da condensação do éter interestelar. Mas considerar muitos efeitos a partir de uma causa única também foi um argumento criticado por Burlamaque no texto de Freire Allemão.

De qualquer modo, o debate permaneceu inconcluso. Tratava-se de um assunto de enorme complexidade, envolvendo muitos fenômenos meteorológicos que confluíam no efeito que se denomina hoje inversão térmica. É interessante, porém, ver como os estudiosos brasileiros debateram o tema, muito embora sua solução estivesse ainda bem distante do alcance da ciência do século XIX.

O Brasil passava em meados do século XIX por um momento de avivamento de sua soberania e de sua cultura. Conhecer sua terra, esclarecer o que acontecia no país, fazia parte dos objetivos dos cientistas da época. A ocorrência da discussão dos nevoeiros secos, por si mesma, já é uma mostra que havia um espaço sempre crescente para as questões científicas nacionais. A querela resultante mostra também como podia variar a apreciação da natureza de um mesmo fenômeno em meados dos oitocentos no Brasil, e como as reputações na ciência surgiam e mudavam. Também é interessante contrastar a forma de pensar a ciência atmosférica no século XVIII, em que havia uma preocupação experimental quase sempre presente, como se vê nos toscos, porém bem embasados ensaios de José Pinto de Azeredo, ou mesmo no caso de João Manso Pereira, com a posição de cientistas do século seguinte, que em muitos aspectos se haviam distinguido por importantes contribuições experimentais, mas agora adotavam uma postura puramente dialética, em face de sua impotência em resolver uma questão de enorme complexidade e além da ciência de seu tempo.

\section{REFERÊNCIAS E NOTAS}

1. Filgueiras, C. A. L.; Lavoisier - O Estabelecimento da Química Moderna, Odysseus: São Paulo, 2002, p. 53-75.

2. Taunay, A. E.; Bartholomeu de Gusmão e a sua Prioridade Aerostatica, Imprensa Official: São Paulo, 1938, p. 119-121.

3. Filgueiras, C. A. L. Em História da Ciência: o Mapa do Conhecimento;Goldfarb, A. M.; Maia, C. A., orgs.; Edusp: São Paulo, 1995, p. 381-390. 
4. Maxwell-Stuart, P. G.; Chronicle of the Popes, Thames and Hudson: Londres, 1997, p. 203.

5. Filgueiras, C. A. L.; Ciência Hoje 1988, 8, 52.

6. Gazeta de Lisboa, $\mathrm{n}^{\circ}$ XXVIII, $2^{\circ}$ suplemento, 17 de julho de 1784.

7. Ibid., $n^{\circ}$ XXVIII, $2^{\circ}$ suplemento, 16 de julho de 1785.

8. Seabra Silva Telles, V. C.; Elementos de Chimica, Real Officina da Universidade: Coimbra, $1^{\mathrm{a}}$ parte, 1788, $2^{\mathrm{a}}$ parte, 1790; Filgueiras, C. A. L.; Quim. Nova 1985, 8, 263; Filgueiras, C. A. L.; Schriftenreihe für Geschichte der Naturwissenschaften, Technik und Medizin, Leipzig, 1991, vol. 27, p. 27-44.

9. Pereira, J. M.; Memoria sobre Huma Nova Construcção do Alambique para se Fazer Toda a Sorte de Distillações com Maior Economia, e Maior Proveito no Resíduo. Sobre a Distillação das Aguas Ardentes. Traduzida do Francez pelo P. J. P. de A. Acrescentada e Illustrada com as Notas de João Manso Pereira, Impressão Régia: Lisboa, 1805.

10. Filgueiras, C. A. L.; Quim. Nova 1993, 16, 155.

11. Pinto, M. S.; Cechini, M. A. G.; Malaquias, I. M.; Moreira-Nordemann, L. M.; Pita, J. R.; História, Ciência, Saúde - Manguinhos 2005, 12, 617-673.

12. Azeredo, J. P.; Exame Químico da Atmosphera do Rio de Janeiro, Jornal Enciclopédico, Lisboa, março de 1790, 259-288.

13. Ref. 12 , p. 264-265.

14. Ref. 12, p. 267.

15. Ref. 12, p. 268. Ar nitroso corresponde ao óxido nítrico, NO. A cor vermelha apareceu pela oxidação deste pelo oxigênio do ar a dióxido de nitrogênio, $\mathrm{NO}_{2}$, de cor vermelho-acastanhada. E ácido nitroso é o nome antigo do ácido nítrico, $\mathrm{HNO}_{3}$, pela reação de $\mathrm{NO}_{2}$ com água.

16. Ref. 12 , p. $272-273$.

17. Ref. 12 , p. 273.

18. Ref. 12 , p. $269-270$.

19. Ref. 12 , p. $279-280$.

20. Crosland, M.; Gay-Lussac - Savant et Bourgeois, Belin: Paris, 1991, p. 52-53.

21. Filgueiras, C. A. L.; Química Nova na Escola 2004, nº. 20, 38.
22. Marques, A. J.; Filgueiras, C. A. L.; Quim. Nova 2009, 32, 2492.

23. Estatutos da Sociedade Vellosiana do Rio de Janeiro; Arquivo do Museu Nacional, cota BR MN.DR, pasta 3, doc. 157, 1850.

24. Sociedade Vellosiana de Ciências Naturais do Rio de Janeiro Bibliotheca Guanabarense; Biblioteca Nacional do Rio de Janeiro, Setor de Obras Raras. - Microfilme PR -SOR 19 (3), 1850-1855.

25. Paiva, M. P.; Associativismo Científico no Brasil Imperial: a Sociedade Vellosiana do Rio de Janeiro, Thesaurus: Brasília, 2005, p. 28.

26. Diploma de Francisco Freire Allemão de Cysneiros da Sociedade Vellosiana; Biblioteca Nacional do Rio de Janeiro, Setor de Manuscritos, Microfilme MS-548(2), e documento ${ }^{\circ} \mathrm{I}-28,05,062$, 1850 .

27. Marques, A. J.; Tese de Doutorado, Universidade Federal do Rio de Janeiro, Brasil, 2009.

28. Vandelli, A. A.; Reflexão sobre a Questão dos Nevoeiros Seccos da Atmosfera do Rio de Janeiro. Apresentada na Sociedade Vellosiana, pelo Snr. Dr. Francisco Freire Allemão, Arquivo do Museu Imperial de Petrópolis, Cota n MS MI Maço 126-Doc. 626313, 1853.

29. Espalhamento elástico da luz ocorre pela reflexão da luz ao atravessar um meio com alteração de sua direção de propagação, porém sem modificação de sua energia.

30. Biblioteca Guanabarense. Trabalhos da Sociedade Vellosiana; Arquivo do Museu Nacional, Cota ${ }^{\circ}$ 500.1, S678T, 1851-1855, p. 106-108.

31. Requerimento de Frederico Leopoldo Cesar Burlamaque para Diretor do Museu Nacional; Biblioteca Nacional do Rio de Janeiro, Setor de Manuscritos, Pasta C-0108, 018, nº 003, de 08 de maio de 1847, com Carta anexa sob o $n^{\circ}$. C-60, 4.

32. Ref. 30, p. 77.

33. Marques, A. J.; Alexandre Antonio Vandelli e as Ciências Naturais, Livro de Anais do Congresso Scientiarum Historia, UFRJ/HCTE, Rio de Janeiro; 2008, p. 324-337.

34. Pierre Marcel Toussaint de Serres (1783-1862), naturalista e geólogo francês. 